\title{
我所看到的蘇聯科㦼院 機械研究工作的情况
}

\section{于 道 文}

中國科學院訪蘇代表专在柇聯的時候，會經 訲問了蘇聯科學院和烏克蘭、泉茲別克兩加盟共 和國科學院。訲問係按照算聯科學院篇我們所安 排的一個栝密的訪問計盽進行的: 先是全體參加 主席團第我們組織的關於蘇聯如何組䢂和領導科 學研究工作的座談會, 然後是分科訪問各研究所, 以便了解焦聯各阿科學的現狀及其發展方向。分 科訪問在機械方面主要到過在莫斯科的蘇聯科學 院機械研究所和在基輔的烏克蘭科學院農業機械 研究所。

磁聯科學院機械研究所, 共去過兩次, 由研究 所的正副所長彼特魯謝維奇和哭日克接見。在訪 問這個研究所之前, 我們曾出席了蘇聯科學院技 術科學部的座談會, 在座談會上聴了該學部的院 士秘眚赫利斯奇安諾維奇關於技術科學部一般情 沉介紹的報告。在這次座談會上還有很多蘇聯的 卓越的科學家, 他們解答了我們所提出來的關於 制訂研究工作計劃以及研究機構與生育部門的聯 熟等等很多問題, 給我們很大的啓發。在機械研 究所訪問時, 除了參觀他們的試驗室外, 並與研 究所內著名的科學家會談。雖然每次訪問的時 間不過幾小時, 但由於蘇聯科學家對我們熱情等

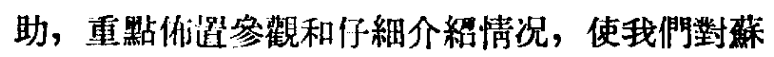
聯機械科學的研究工作, 得到了初步的認識。

現在就我們所看到的和聽到的報道如下:

\section{一 蘇聯科翼院獾械研究所的情况}

蘇聯科學院技術科學部院士秘書赫利斯奇安 諾維奇在介称技術科學部的各研究所的工作範圍 時, 說這些研究所所研究的是技術科學上的一些 需有普㴜性的重大理論問題, 必須由各方面的專 家公加始能解决者。因此, 機㭜研究所所進行研 究的中心問題大致上是機械設計和教工上的科學
理諭根據。

談到機㑘研究所的研究方向, 首先要注意在 蘇聯製造和廣泛應用高生尿力的現代化機械設 借有着䁰等的重要性。馬林科大间志在第十九次 黨代表大會上的報告中曾指出過: “穌聯勞動生產 率的迅速提高, 首先是由於國自經湾中廣泛地使 用新機器和探用先淮的技矿作業法、生噇機械 化和電氣化，特別是貿力的、沉重的工作機械

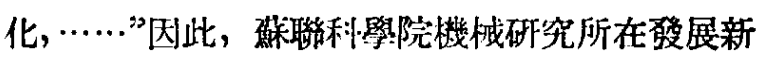
型機器製造技術方面有很重大的任務。正如同琵 聯科學院院長涅斯米掦萑大院士在他的“在蘇聯 共產黨第十九次代表大會决議的啓示下櫯聯科學 院的幾項任務”一文中所指出的: “創造近代巨大 的、快速的、具有高度生產效能的機器的必要性, 向有關機械的科學部閏提出了新的複雜的任移, 篇了完成選些任移需要應用完善的、新的計算求 法與試驗方法, 承决定機器中的應力、戀形和振 動。在這種情况下, 研究的具體對像首先是像强 大的渦輪發電機、水力渦輪、蒸汇渦輪、吸泥機 等這類的機器。”

現代化的機器, 要具有高的效率, 常使用高 的運㯖速度, 並向自動化弡展。就熱力發電設借而 言, 過去蒸汽渦輪墢電機技大的僅有 25,000 千正

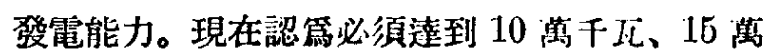
千瓦, 效率才高。因此在材料上、結構上、施工 上有很多問題。10萬千正的渦輪發電機, 它的轉 子重 70-75 瀬, 轉速每分鐘 3,000 轉, 動力學上 應當穞定; 而機器又不能有很大的重量。这便是 機械研究所應解决的問題。

這些問題並不砈是在動力設備方面㡎生, 其 他如在工具機械方面、士建機械方面也是如此。總 之, 研究怎樣提高效來, 加强生產能力, 是一般 的方向。在設計新機器時, 尤其應當注意到提高 
機器的善命和隇輕機器的重量。這方面要求機件 强度、磨損、澗滑等理論磔究工作的發展。另外因 篇製造新型機器和動力設備的需要, 還必須注意 酎熱材料的研究，例如 15 萬千瓦高效率的蒸汽渦 輪就使用着 170 大氣㗛、 $550^{\circ} \mathrm{C}$ 的超高温、超高原 的過熱蒸汽。目前的起勢更是淮備過渡到利用更 高的温度和更滈的聮力, 如 300 大氣圈和 $600^{\circ} \mathrm{C}$ 的温度。

機峨碑究所目前共有下列 10 個研究組, 各組 都有試騪室。選 10 個組是:

(1) 普通材䉼倵驗組;

(2) 㬏温下金屓强度組;

(3) X 光相學組;

(4) 機器零件强度組;

(5) 變形及應力研究組;

(6) 機伐動力學組;

(7) 摩擦與磨損粗;

（8）儀器及機構淮確性組;

（9）機械慗造工㢣組;

（10）機械傳動組。

第了使大家能對機械研究所有一個概括的瞭 解，我們把這次害觀到的各研究組作一介紹。

\section{1.普通材料試驗組}

道個研究組的任務是研究常温時金䀛材料的 一般性質。主要試驗設㸴有萬能材料試驗機、行 笔材料試驗機和疲勞强度試驗機。

逐個研究組由機械研究所副所長吳日克符任 領導，呂日克會對金屈材料强度及断裂抵抗作了 很詳細的研究。當我們寗觀這個組的試驗室的時 侯, 他親自把試驗室的工作做了倜簡單的介紹, 說明迺件工作的重要性。他說: “圆柱形的機器零 件若直徑不是一致的, 例如有凹口, 則承受載荷 時有應力集中現像。在研究所裏曾取過有凹口的

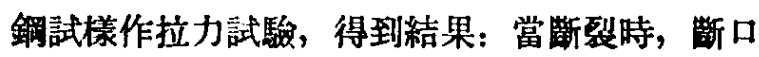
沒有縮細的現象; 在斷口外圈現黑色, 根據 $\mathrm{X}$ 光 相學的研究結果, 得知造是塑性變形部分。數學的 繁雜計算所得的結果和試驗所得的結果有近似的 關係。以後文作了關於承受拉力及扭力的複合載 荷的試驗。機件上的礁力不是均匀的, 第了更合 理地使用材料, 試驗材料時不礁該忶取光圆柱形

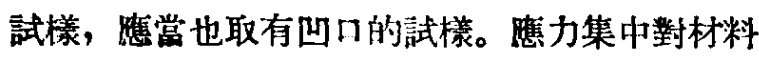
强度的影響, 各國都沒有很多的數㨜, 但逼是非
常重要的。”在迢件工作上, 吴日克還進行了低温

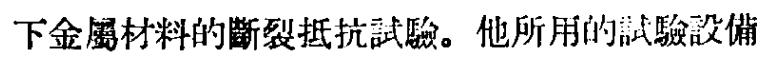
如下: 一個盛有莱的隔熱回简安琵在萬能材料試 驗機上，陚核放在落內。在回筒內試樣的週圍有蛇 形管，管中通以液體氮或受。此装置可以保持低 温 15 分鐘, 試驗操作在 15 分鐘內作完。得到結

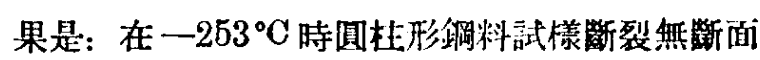
綰小的現像。(只日克研究結果寥看他所著“金显 材料的斷裂抵抗和强度”一書, 缷聯科學院 1950 年版)。

\section{2.高温下金国强度組}

道個研究組由通訊院士奥金叮領導, 研究在 高温下金圆的强度問题，進行耐熱金屬在高滥時

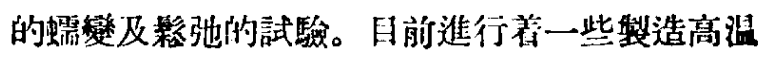

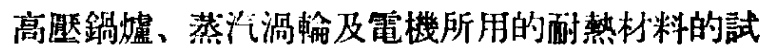
㹂; 將所得結果畫成圖表，㚱設計工程師隹用。

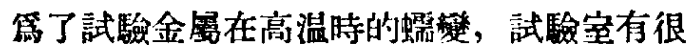
多架蝠變試驗機, 試䮑温度範圍自 $500^{\circ}$ 至 $800^{\circ} \mathrm{C}$ 。 在試驗機上試樣俰由一圆筒形䉓爐加熱, 洼到一 定温度後加入一定的載荷, 以後载荷不再變更。 變形係在一個 $1 / 1000$ 的指示表中壊出, 每 5 分鐘 記錄一次。在試䮑過程中，温度督化不得超過 $1^{\bullet} \mathrm{C}$, 有自動斷續電流之調節裝通。載街一般祇用 拉力, '但試駼機上有輔助裝備, 能再加入扯力載

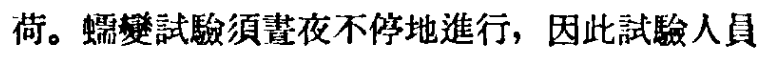
分 3 班接替，每班包括工程師、算驗員和電工各 1 人。每試驗須繼續 1,000 小時。根據所得數字 製成時間與百分綡形的關係曲線。

承受載荷的金感材料在高温經過一段 時間 後, 因座生了塑性䙪形的線故, 應力漸減, 此現

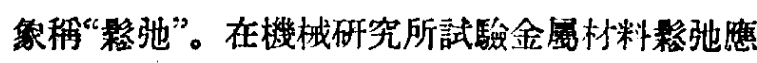
用了一個新的力法，大致如下: 部核製成圆园形 而具一隻斜開口。在開口間放一楔, 使試樣承受 一定的㮣力。將試樣放在横试圆形電嘘中保持高 温。每隻電嘘可问時放入試樣 25 件。每隔一定的 時間, 陸續取出一件試樣, 冷却後测量開口的樂

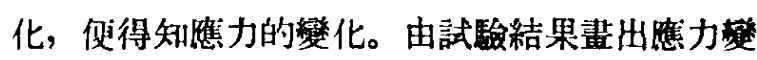
化與時間的關係曲線。

研究酎熱材料的强度，䋩必須試驗材料在高 温下的裂斷抵抗和在高温下的疲筞强度。機械研

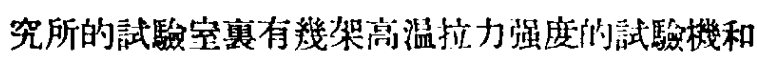

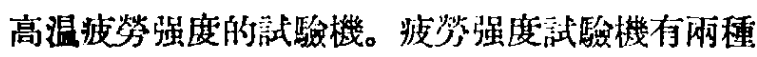


類型：橫式的和立式的。

螇變的試驗一般秪做 1,000 小時, 而在惯際 機器的使用上，材料工作常達 10 萬小時。因此必 須在理論上研究金屬在高温下怎樣货承受載荷, 也就是金屬在高温下的强度問題。這一方面要求 借助於X 光相學的方法來研究金偈的結晶組織在 高温時的變化規律。

\section{3. $X$ 光相學組}

通個研究組的任務是根措金鹿的X 光相的分

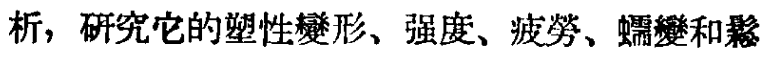
弛。由X光的干涉圖看晶格的大小，研究金屬的 性質以及受到塑性縋化時的結晶組 鐡。

在X光相學試驗室內有一架主要的X光相儀。 試樣係按放在一個輔助裝置上。試樣可以連裝㯰 一同取下隶, 然後放在材料試驗機加上載侍, 使 試樣產生變形，再放回去照像。另外有兩個 儀 器: 其一篇一個萬能材料試驗機和 X 光相儀的聯 合裝置, 其另一霨葚空式X光相儀。

\section{4. 機器零件强度組}

這個砤究組是由烏克蘭科學院院士謝林新領 導, 研究重要機器零件的强度, 在㖟驗上和理論 上加以分析, 做出機器䇰件設計的依據。

以下是所長彼特魯謝維奇介紹選個組的工作 情况:

機器零件强度組進行了很多大尺度的僡動軸 的研究工作。先在理論上分析由於垂直於軸的力 所引起的振動以及载㫦與振動的關係。蒉驗方法 則係應用電阻變形儀。篇了試駿大尺度的傳動軸, 這個研究組會設計了新的試驗機, 能試 驗 100200 毫米值徑的軸, 潈個試驗機現放在列察格勤 的“電力”工廠內。在研究所裹祇有一個試驗 60 毫米直徑以下的軸的裝置。

目前這個組所進行的理論工作是大人度的軸 的界限速度及共振現象之研究。更對蒸汽渦输的 轉瞥、水力渦輪的旋槳作了模型試驗; 研究它們 的振動形式和振動部分。關於水力渦輪旋槳的模 型振動試驗, 研究方法是使用沙子, 在振動部分 沙子集中。

研究水力渦輪機軸在與軸垂直的方向的振動 時得到了這樣的結果: 線性振動(即可以用線性微 分方程式表示的振動）在受有外部及內部摩擦之 情形下，㗂用複變數函數可以很简單地表示出
來。

层動現象與機件材料的關係很大，不同的材 料吸收功能的程度不京, 因此作了彆造水力渦輪 旋槳用的材料吸收動能的實騟研究。

此外罢研究過曲軸的强度和振重加的問題。

總之, 目前對高速的機器, 振動的研究是很 重要的。1952 年曾由機械研究所主持召開過關於 渦輪振動研究工作的報告會。

機器零件强度組的另外一項工作是研究如何 在設計上和施工上提演機件强度, 具體實例如彈 签。此外還注意到各種不同形式的表面加工，例 如化學蓺處理、高週波電流淬火以及冷加工硬化 等對機件强度的影響。這些工作已發表篇論文 集。(見“機器零件强度的的提高”蘇聯科學院 1949年版)。

除了以上所迅，機器零件强度組還作過胡崘 傳動强度的理論研究工作, 並且在工做衰進行了

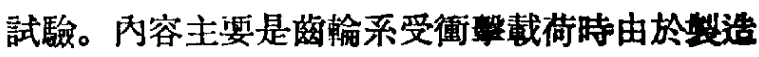
的不淮確程度所產生的動載荷。

在訪問過程中，所長彼特魯謝維奇又歌到雅 庫雪夫候補博士的博士論文: “螺牙接合强度的 研究”。這是在另一個研究機構 (航空工業部的一 研究所）冥進行的鏆驗研究工作，將在機械研究 所舉行答琣。全部諭文原稿 600 餘頁，對於各稙 式樣、各種材料的螺釘以及如何增加里牙接合的 疲勞强度作了很詳細的研究。

\section{5.變形及應力研究組}

研究機器零件承受載荷時的變形和應力有二 種情形: 一是研究機件上各處應力分佈的情况， 一是研究機件當機器工作時的應力的變化情况。 茲分別說明之:

甲.研究機件、上應力分仂的情况:

研究方法除了可以應用電阻戀形儀外，台有 下列二法, 即偏光彈性法和表面染漆法。

用偏光彈性法不僅可以研究應力在蹘質模型 上的平面分倠情况，也可以研究應力在不同厚度 方向的分佈情况。研究在厚度方向的應力分作, 從前的老辦法是在偏光彈性試駼機上加入載荷, 以後將膠翼模型的温度坦加，如此在模型中産生 永久戀形，冷却後將模型切成幾片而分别觀察。 現在這個研究組有新設計的立式偏光 彈性 試 驗 機, 偏光自下向上發出，形狀是很薄的一片，照 
到模犁上䫏示出一個斷面㶐力分伽情况，不必將 模型切片。

表面染漛法的原理, 係在機件或它的模型上.

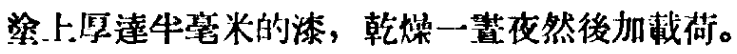

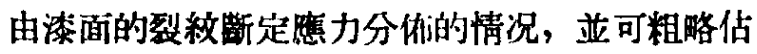
計應力的大小。

乙.研究機件當機器工作時的應力維化情况: 研究方法一般叮以利用電阻變形儀。機件在 機器上的工作條件是多樣的, 有的須長時間測量 它們的答形; 有的是承受着一刹那間的㣫等载街。 須用羢器記錄由載荷所引起的應力戀化; 有些機 件在水中工作, 測量掱器須不怕水; 更有些機件 以高速而旋喠。機棫研究工作者必須先設計笠造 出很多適當的儀器來, 才能完成工作的任秝。

以上各種試驗工作的實際意義如下: (一)計 算機器零件所承受的载荷, 由理論不能得到淮確 的結果，(二）根譃彈性力學計算應力分雄的情况 记能得到粗略的数字，必須加以測量。但是必須 深深地瞭解理論分析，才能很好地運用筫驗方法。

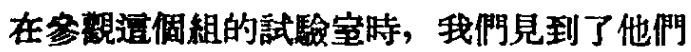
目前進行的幾項工作:

(a) 研究 15 萬千互活動旋獎式水力渦輪上的

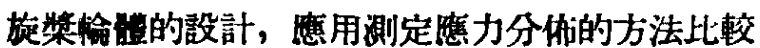
雨個不同的結搼。遗一個機件的實物 重 量

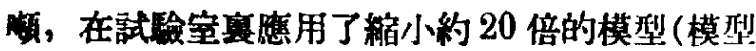
可以用與實際機件相闹的材料慗成，或是用膠質 材料製成)。載衡按照實際承受方式加上去, 但量

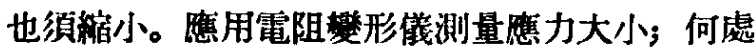

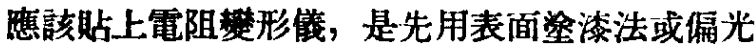
彈性法預先粗略找出來的。

（b）篇偉大共產主義建設的水力發電站做出 測定水力渦輪在惯際工作時旋獎各部分所受水的

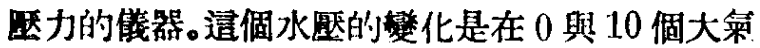

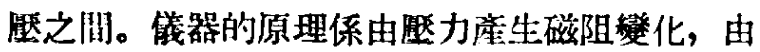
磁阻變化座生電流，經放大而以陰極射綫示波器 現出。

（c）篬了測定水力渦輪在實際工作時各部分 的振動, 試驗室又正在製造測量振動及其加速度 的儀器。儀器利用厭電晶體因機件振動受壓而產 生電流, 並把選電流放大而以陰極射緎示波器顯 出振動情况。

以上雨種儀器都被作成直徑約 1 厘米的溳餅

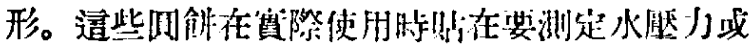
振動的地方, 再以集線聯接到管理台与, 在台上。 有放大裝造和㓌極射䋨示波器以及很多電鉦。

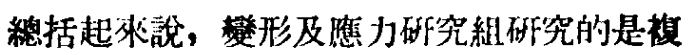
雜的機件的綎形和應力, 做什没計造些機件的理 論根摸、計算方法和試驗方法，也就是研究怎梯、 科學地承設部和䌘造機器。

\section{6.機悈動力學組}

研究機器運㯖情况, 常須测定機器某些部分 的位移、速度或加速度（通線的或角的）, 或所承 受的力、排矩等, 因之需要一些特種儀器。機械研 究所的機械動力盁組的一项重装工作是創製合乎 焂件的儀器, 以健用來㸴究機器的運轉, 改進機 器的結看。

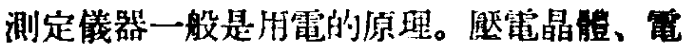
阻、電感憵、電容以及磁阻等场理都可以利用來 作出测定力學量的儀器。把浇调䉓阻變形儀組合 起來，還能够做出若于新的儀器。

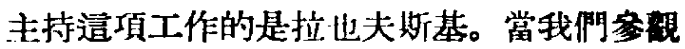
造個砋究組的試驗室時, 他会給我們看利用䉓 阻經形儀的原理製作出來的测定振動的儀器。儀 器的主要部分是一-個值立的金氛片, 下端固定, 上端有鋼球，它可以㨢動。在金屬片的两丽面各貼 有一個電阻戀形儀。全部俄器是在一個小玻玹罩 內。當儀器放在振動的機件上.時, 鋼球金易片随 機件而振動, 則兩電阻變形儀器一個受拉伸, 一

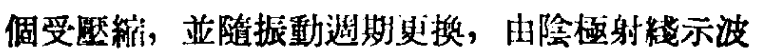
器便得知振動之頻率及加速度。

這個研究組作出來的各项儀器不僅有篇了研 究機械動力學用的，其他如测量金忽切削機床上 刀具所受的切削力, 研究笛動機起動時加速度之 㜻化等用的儀器也能够根據遭些原理製造。他們

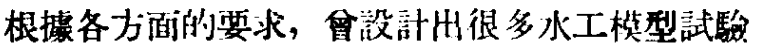
用的测量儀器（这些水工模型試驗大都是關於偉

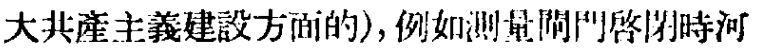

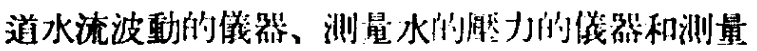

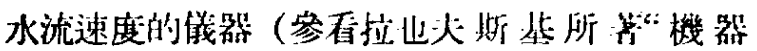

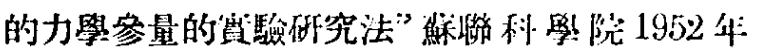
版)。

\section{7.摩擦與磨損組}

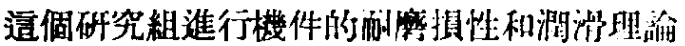

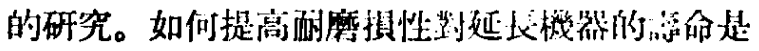

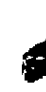

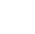

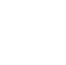

$+$

.


很重要的。

他們篔進行過吉型的水力渦輸的立式油膜軸 承的模型試駼。古比雪夫水電站的水力渦輸上的 軸承萠力是 3,500 吆; 模型較小，徭取了 100 懒。模型上.有履塊 16 鸤, 在實際機器上可用 24

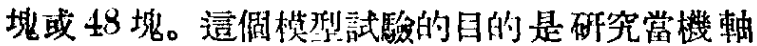
起轉特潤渭油飛賎的情形, 以便修改結構, 使它 能承受最大的磨損。還利用了熱電偶测定履塊上 的温度分倠情形，畫约等温線，以便决定如何冷 却。

第了進一步研究金啳的酎譄損性及被磨損的 機件，必須考杰它們的組織。在摩擦與磨損試驗 室內有一些研究金屬在滈温時結晶組織的儀器。

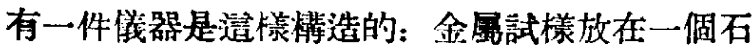

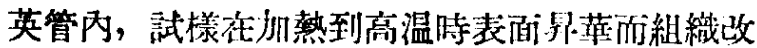

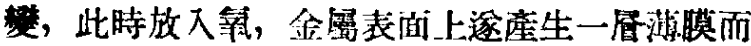
固定，然後將試樣取下放在金屬顯微鏡下觀察。 另有一架高温下微最硬度計，温度可荙 $1,000^{\circ} \mathrm{C}$ 。

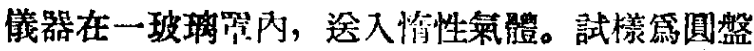
形，可以旋轉。有 6 個金唋石㻌頭，但位於 6 個 直徑不等的同心圆周上。試樣何次旋轉 $1 / 10$ 圆周 ，因之可在同一就樣上作出 60 個不同的針穴。 即可以测出 60 種不同條件下的硬度。用遗個倩器 也可以研究金镯的老化現象。

以上是機械研究所 7 個砳究組的情况。

由於機件工作的新焂件，現代化機器要求更 加椱雜更加巨大的機件, 要求機件構造和機能的 商度準確性。因此就需要在運動學和動静力學上 分析機構和機作組合亚進行䃑究, 制定機件淮確 性的理論。潖便是儀器及機峨㒕確性組的研究目 標。對於儀器及機棈準確性組以及機械傅動組, 因篇時間關係，未會進行瞙解。

機械研究所過去在機械製造工藝方面的工作

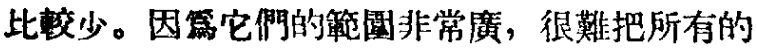
問題都包括進來。另方面在各工業部，㯰方面的 研究所已經很多。高等學校有關機械整造的專業 嫩研空在通方面的工作也作了很多。在我們訪問 的時候, 特別向所長彼特鲁謝維奇詢問這方面的

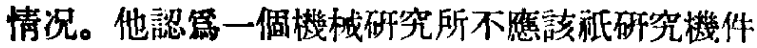
的强度，也應該對機械製造工蓺上的理論進行研 究。

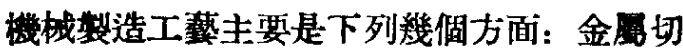

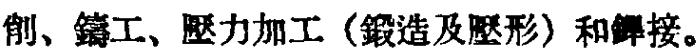

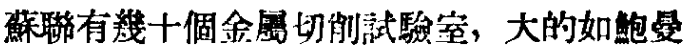
高等工程學校、中央機悈製造及工㙯研究所和機 朱工具研究所裹的。在蘇聯科學院機械研究所的

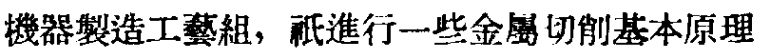
上的問題的研究，那些題目是與各工業部的研究 所或高等學校裏的題月不相重複的, 例如: 㬏速 切削刀具的磨損 (利用放射性问位素); 金易在 切㓩過程中的塑性變形與接觸應力; 切㓣温度及 熱傳導的關係; 瓷質燒結切制刀具的强度問題。

鉒工方面的研究工作在中央機械䌘造及工禁 研究所和很多鋼鐵學院的教研空中進行。

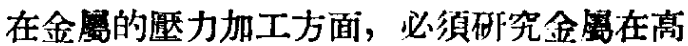
温的抵抗和塑性戀形規律。在蘇聯科學院的力學 研究所和冶金研究所分别進行着理論性和筫驗性 的工作，機械研究所則負責兩者的聯采和交流經 䁩的工作。

在錦接方面，蘇聯科學院技術科學部有錦接 試驗室，烏克蘭科學院有電錦研究所。

目前機械研究所特別注意流水作業生產和機 械化及自動化的理論問題的研究。在計劃中買預 備成立幾個有關加工過程及自動化的研究組。它 們名稳和任務是:

（甲）表面光潔度組：研究機件表面光潔度對

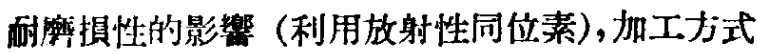
對表百光潔度、䩂磨損性的影響。

（乙）精密度組: 研究機件在施工過程的技術 測量的自動化，做江一些儀器來不但能检驗機件 是否在所要求的公差內, 並且能自動將合格與不 合格的機件分開。

（岢）自動作業線及機欟組：研究自動運翰的

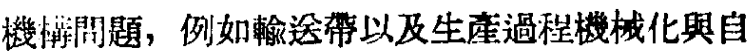
重化的理論問題。

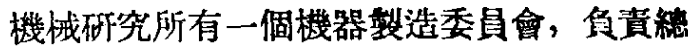
結生座經驗, 傳播先進技術。並且時常組樴報告 會，激請工業上的革新者來莫斯科作報告，使生 原革新者和科學家結合起來。像浸近强力切削法 的創始者科列素夫和機床振動消除器的設計者雷 日科夫都曾來到莫斯科機械研究所作過報告。

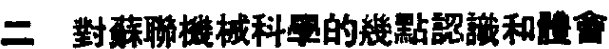
10 月號
科學 通 報 
訪問了葆聯科學院機械研究所以後, 對蘇聯 械科學研究工作有䋐點認識和體會, 寫出來與 大家商檴。

（1）科學研究工作的目的性和計劃性。

蓕聯科學以擗證唯物主義和歷史唯物主義篇 基礎, 研究自然與社合的客觀法則, 並運用這些 法則永社合謀稫利, 所以有鮮明的目的性。斯大 林指出社會主義基本經橓法則的主要特點和要求 是: “用在高度技術基礎上使社會主義生產不断增 長和不断完善的辦法, 來保證最大限度地滿足整 個社會經常增長的物質和文化的需要。”高度技術 的建立、生産過程進一步的機械化和電氣化，決 定於大機器工業的發展。在蘇聯, 機器彆造工業 被看作一切國民經濟部門中技術進步的基礎。硶 聯機械科學研究工作的目的也就是第了完成發展 新型機器䌘造技術的任務, 篇共產主義建設 服 称。

由於鲜明的目的性使蘇聯科學工作有高度的 計劃性。蘇聯科學院在制訂計劃時, 首先研究當 前國民經渓計劃的要求、各門科學的現狀及其融 展透最, 以確定主要研究方向, 即所謂科學的生 長點。機械學是一閶較老的學問了，大多数的問 題似乎都研究過; 但也有它的生長點, 那便是機 器䡈造過程的自動化和遠距離操縱問題的研究。 由於電子學的成就, 使我們能彆造一些設備, 把 它們和機器與機床聯合起來, 便能自動管理。涅 斯米揚諾夫院士在 “在蘇聯共虐黨第十九次代表 大會决議的啓示下蘇聯科學院的㳀項任務”中說: “整造在人們的控制下能够獨立自動地進行工作 的機器、機床、機林線、自動化工廠、動力設借 是共應主義建設時代的特徽。勞動生座率極大規 模地增長着。人們㨢脫了沉重的體力勞動——這 是消堿體力勞動與腦力勞動的本質差别的前提之 -。”

（2）研究機構和生产部門的密切合作。

在蘇聯, 科學和生產的創造性的合作, 無疑地 是科學發展的一個重要因素。科學家和生䒚革新 者們利用實際經驗來買富了科學, 同時可以更好 地和更快地解决筫際問題。我們所看到的和所聽 到的都馀明: 蘇聯科學院的各研究所和生產部門 聯系得非常婜密。機械研究所有砤多試驗工作就 在工倣衰進行, 設備安置在工廠裹。蘇聯科學院
力學研究所潐備把新的試驗設備作成活動試喰台

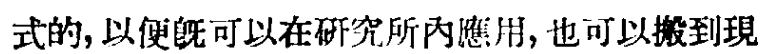
場工作。葆聯科學院的冬研究所紃常和各工業部 的代表組織工作榢到偉大共虐主義建設施工地 點(例如古比等夫水電站)共问發掘問題, 然後提 交共產主義協助委員會鱕烃，再經主席團批准轉 交下來, 制訂在研究計劃中。磻物燃料研究所自 組糡過訲問團到頓巴斯礴區去訪問。訪問的目 的: 一方面是检查研究所的研究方向是否正確, 另方面是暸解廠碳的贯際情况，看是否有其他問 題需要研究。

當我們在機㑘研究所和奥金克通訊院士會談 時, 他說: 䌘造巨型的蒸汽的以及水力的渦輪, 現在總算有了成就。在設計和聲造的當中曾遭遇 到了不少的難題，但也克服了不少的困難。大建 設需要各方面人員共同努力，才能涬到目的。科 學與生產相結合，相互緊密聯橧是成功的主要原 因。

(3) 研究問題應用馬克思列酊主義觀點。

薜聯的科學研究工作, 是辟證唯物主義思想 的具體應用。他們十分注:意各㮔現象之間的相互 聯系; 雼了解决一個問題, 他們從各個方面進行研 究。例如，烏克闌科學院結構力學研究所研究金 俤的耐疲勞强度，不僅要研究金显在空氣中的情 况，還要研究金属在其他物新（如水或油）中的 情况，籍此以膫獬機件在不问的環境中墢生什㛢 影響。研究金䐂强度問題，不僅要研究外部作用 對金屬强度的影響，问時也研究在製造過程中所 發生的對金屬强度的影響，也研究在養護過程 中和使用過程中金盛强度的化。

蘇聯科學院物理化學研究所李賓德爾院士估

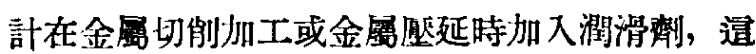
潤滑溂對金屬一定有化學作用和力學作用，因之 加以研究, 並將研究結果應用到生產方面。在切 㓩時由於一種㵎滑劑的物理化學作用使金显工作 件表面産生塑性形，切別刀具的磨損因而減 低, 在掭力加工方面, 由於一種潤滑洌的物理化

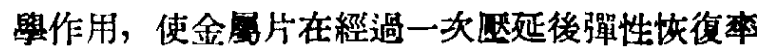
減低，大大地降低了加工成本。

（4）探用理論與䁈驗相結合的方法，並應用 最新的原理。

首先我們認識到蘇聯在研究工作中常探用理 
論和實驗相結合的方法。對於機器零件或機件組 合的設計研究，探用計算和試䮦相結合的辦法。 先根傢理諭用計算方法（例如油膜軸承根據流體 力學及潤滑理論）算出，再使用模型加以試驗， 由試驗䊅果改進設計，也可以改進計算方法。這 樣，計算方法與試驗方法相互不斷地提高。

研究機械常須作一些測定, 例如研究動力學 須要測定速度、力和振動等, 研究結構强度須嘍 测定變形和應力等。因此研究新的測定儀器或設 計特種試驗裝置便成第機械方面的技術科學工作 者的任䅂之一。蘇聯技術科學工作者早已很好地 解决了这個問題, 並且儘量應用基礎科學所供應 的最新的原理, 以便使新作出來的儀器能得更精 確的結果, 澾到更高的要求。機械研究所試驗金

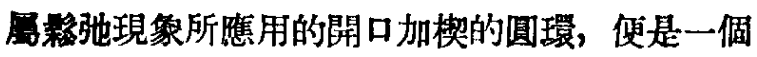
新穎而簡單的方法。此外放射性同位素在研究工 作中的應用, 在蘇聯很多研究所已廣泛展開, 機 械研究所研究刀具的磨損就應用了它。

當我們在蘇聯科學院冶金研究所訪問時，該 所所長巴爾金院士也會談到: 中國應先對一般的 合金鋼和它們的鳃接的問題進行研究。研究方法 上應䜻量探用新的方法。

(5) 批評與自我批評的運用。 批評與自我批評是推動蘇聯科學發展的巨大
力量。蘇聯科學界無論在那一門科學都廣泛地展 開不淮意見的争論和批評。機㳦研究所經常組織 的“科學討論會”就有 5 種之多（機構及機 械原 理、儀器及機構準確性、機器零件强度、摩擦與 磨損、汽車原理等 5 種)。其中“機構及機械原理” 討諭會, 自該所成立以來即有, 到現在出版的專 刊已有 50 多集了。在各種科學討論會上, 並不限 於本所有關的研究人員, 凡是對這一閏學科有興 趣的都可以疹加，生產部門可以由個人寥加或派 正式代表寥加。在討論會上學者們都第了真理的 追求，都熱烈地提出意見並誠愁䇣值 地 相 評。

蘇聯報紙的批訴對於科學研究工作的墢展有 很大的推動作用。1951 年真理報的社諭批評機械 研究所和技街科部其他研究所的工作與工業脫 離，對於工業上的新成就有不閣心的情况。逐些 批評對研究所起了很大的皘極作用，改進了他們 的工作，加强了他們和生産部門的聯繁，在他們 的研究計劃中出現了重要的研究題目, 如工做自 動化, 消隇在研究有關機械彆造工㙯問題的缺陷。 在 1952 年技鿉科學研究成果的推廣增加了兩倍, 研究工作的實際意義也更爱加大。在技術科學部 的座談會，奥上金克通訊院士曾特別對我們談到 通些。 